five grains of calomel and two of camphor temples, completely removing the cerebral were given, as slight cramps were felt in the excitement, and reducing the frequency of lower extremities, and the stools continued the pulse. The simple effervescing salines untinged with bile, but less frequent. Sim- were continued every two hours, and five ple effervescing draughts were given every grains of calomel were given at bèd-timé, two hours, and grain doses of calomel when no pain or cramp remained, and the every hour, until the secretions resumed heat of the surface wis equable over the their bilious character; the urine was body. The purging had also ceased since plentifully secreted on the 21 st. The con- noon. In the night urine was plentifully secutive fever, which was rather high, was secreted, and on the morning of the 23rd treated upon general principles, and in six it was found necessary to administer a dose days the patient's health was re-established, of castor oil, which procured a copious with the exception of weakness, and the bilious evacuation, after which the secuinconvenience produced by the blistered surfaces, which being very extensive were proportionably long in healing. This patient took 22 grains of calomel only, and 25 grains of carbonate of ammonia. It was on account of the patient's excessive thirst that the effervescing salines were exbibited so frequently, and also in consequence of his great partiality to them.

CASE 2.-W. E., æetat. four years and two months, was seized at midnight, on the 21st of August, with purging and vomiting of a fluid resembling rice-water, which continued very frequent until three a. $m$. on the 22nd, when 1 first saw him in a state of collapse, and suffering trom cramps in the extremities and stomach, over which I directed a sinapism to be applied, as well as others to the soles of the feet, and frictions to be incessantly used to the extremities. I ordered strong brandy -and-water to be given occasionally, and a powder immediately consisting of four grains of ealomel and half a grain of camphor, which being soon rejected by vomiting, was repeated. When I next visited this little patient at seven a.m., and found that the sickriess contirued, and the pulse was still imperceptible at the wrist and carotid arteries, I obtained Mr. Rutherford's sanction for administering an effervescing draught containing two grains of carbonate of ammonia in excess, which completely allayed the vomiting, and enabled him to retain another powder containing five grains of calomel, half a grain of camphor, and a quarter of a grain of opium, as the crimps continued, and we were doubtful whether all the previous dose of calomel and camphor had been retained. As the sinapisms also had not acted, they were renewed, the frictions continued, and an effervescing draught administered every half hour (each draught containing two grains of carbonate of ammonia in excess), until thirteen doses, or twenty-six grains of carbonate of ammonia, had been taken, when reaction speedily took place to more than the desired extent, as the pulse soon rose to 120 in the minute, and the head became affected, so that the stimulus was of course instantly discontinued, and leeches were applied to the tive fever alone remained to be treated, by mild aperients, diaphoretics, and the effervescing salines. On the 25th the patient was convalescent.

ALKALINE REMEDIES IN

\title{
NALIGNANT CHOLERA.
}

\section{To the Editor of TuE Lancer.}

SIR, - Since the cholera broke out in England, statements of various cases have appeared weekly in T'ue Lascet, treated by the most opposite means with nearly equal success ; so that the young practitioner is so bewildered on encountering the disease, as hardly to know what remedy to employ, but in most instances he is impressed witli the idea, that he has to combat a most formidable disorder, and of course chooses the most powerful medicines and doses for the purpose. The croton oil, calomel, opium with brandy, and other stimulants employed liberally, form the materia medica on most occasions. My object is not to detract from the merits of the above remedies, but to give the result of about 100 cases successfully treated on a principle laid down previously to the employment of medicines, for without some notion of the cause of the disease, it is impossible to have a clear conception of the effect of remedial agents.

The cause of the disease, I have not the least hesitation in asserting, from repeated experiments, to be a superabundance of acidity in the prime viæ, produced by the effect of infectious air, or by the combined operation of other substances.

Having a*certained the cause, the appropriate remedies will be obvious. At the commencement of the disease, for the purpose of correcting acidity, as well as of removing crudites that may be lodged in the stomach, I invariably give

$$
\begin{aligned}
& \text { Pulv. rheri; } \\
& \text { Mag.calimat.a. Эj. M. }
\end{aligned}
$$

Afterwards, two tablespoonfuls of the following mixture after every motion, or the same quantity every two hours, in case 
"the bowels ate not relaxed oftener than once an hour :-

$$
\begin{aligned}
& \text { B Cretexht. } 3^{\text {iiss; }} \\
& \text { Sode carb. } 3 \text { ij; } \\
& \text { Ammon. carb. gr. xv. } \\
& \text { Tinct.opii } \mathrm{ll}^{\mathrm{l}} \text {; } \\
& \text { Aq. cinnam. } 3 \text { iss ; } \\
& \text { Aq. distillat. Zुivss. M. }
\end{aligned}
$$

When there is constant vomiting, a hlister applied to the chest, with the above mixture taken in a state of effervescence, with one drachm of tartaric acid, divided into six porvders, to be taken as above, never fails to remove $i t$.

I have given the above medicine in the first and in the collapsed state, but when reaction takes place, and the tongue be. comes red and dry, then the mixture must be altered according to circumstances, only the same principle being pursued of making use of alkaline remedies.

It may be urged that the cases which have fallen under my notice were those of English cholera, I however affirm, that some of the same family, apparently not so bad, were treated differently, and died in nine hours. Brandy administered in some cases of collapse I have found little better than poison; toast and spring water were only allowed.

So confident am I of the preventive as well as the curative properties of alkaline remedies in cholera, that I sincerely hope that those members of the profession engaged in visiting patients labouring under the prevailing epidemic, will not neglect to use them. Yours, \&c.,

28, Bunbill Row, Finsbury,

$$
\text { David Lewis. }
$$

Sept. 25, 1832.

\section{CALCULUS IN THE BLADDER}

TREATED BY

\section{PERCUSSION.}

\section{To the Editor of Tne LanceT.}

SIR,-I beg to forward to you the history of another case of stone, treated successfully with the "percuteur courbe à marteau," and just transinitted to me from Paris by my friend Baron Heurteloup. I am directed by him to announce his intention of also transmitting to you a paper on lithocenosis, as soon as it shall have been read at the Institute of France. I am, Sir,

Your obedient servant,

Sept. 25th, 1832.

$$
\text { D. O. Edwards. }
$$

\section{CASE.}

Mr. Barber, stat. 61 , a painter, residing at Nottinglam, experienced about a year ago, without having observed any previous symptoms, frequent and urgent inclinations to make water, and occasionally pain at the extremity of the penis. These symptoms for the first nine or ten months, were of so gentle a nature, that Mr. Barber, far from attributing them to their real cause, paid but little attention to their progress, and even thought it unnecessary to seek for medical advice. About this time, however, being called upon business to Northampton, he was inluced, whilst labouring under a more severe attack than he had until then experienced, to consult Mr. Carr, a surgeon of that towri. This gentleman, without sounding, judged by the symptoms that there was a stone in the bladder, and strongly recommended Mr. Barber to go to London and consult Dr. Prout. This advice was followed without loss of time. Dr. Prout corroborated the opinion of Mr. Carr as to the existence of stone in the bladder, and prescribed appropriate medicine for giving immediate relief. Mr. Barber then addressed himself to Mr. Brodie, who sounded the bladder, felt a stone, and kindly recommended the patient to me.

A careful exploration with the rectomcurvilinear catheter, enabled me to discover a moderately capacious urethra, a bladder of the usual dimensions, regularly conformed, and but slightly contractile. The calculus appeared about an inch in diameter, smooth, moveable, and rendering a dry sonorous sound. The urine contained a little albumen, and was voided in considerable quantities.

Mr. Barber was in a fapourable condition for the operation of lithotripsy, and in two short applications of the percuteur courbe, the stone was sufficiently reduced to be completely evacuated.

Mr. Burber was operated on in presence of Mr. Howship, Mr. Lawrence, Mr. A. White, Dr. Bright, Mr. C. Brooke, Mr. Tarral, \&c.

Reflections.-This case is simple, and, with the exception of the rather advanced age of the patient, does not give rise to any very interesting remarks. We may look upon Mr. Barber as having been in a favourable condition; and all patients afflicred with this serious complaint, who, like him, apply for relief whilst the stone is still small, the bladder healthy, and moderately sensitive, and the urethra sound and sufficiently copious, will always derive from the operation a speedy recovery, mostly unattended with pain, and almost entirely deroid of danger. Can the same be said of lithotomy, when practised under equally favourable circumstances? And can the surgeon who practises it, whatever be his skill and talent, give the patient a similar assurance of success? For a long time fre- 